\title{
A Numerical Solution for the Turbulent Flow of Non-Newtonian Fluids in the Entrance Region of a Heated Circular Tube
}

Prapat Wangskarn

Cleveland State University

Bahman Ghorashi

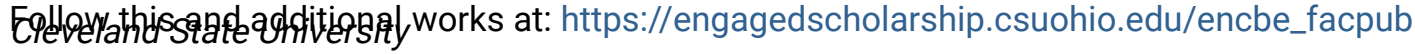

Ramar Subba Re Reddy Gorla Fluid

dreveramassateensivershis work benefit you? Let us know!

Publisher's Statement

NOTICE: this is the author's version of a work that was accepted for publication in International Journal of Heat and Fluid Flow. Changes resulting from the publishing process, such as peer review, editing, corrections, structural formatting, and other quality control mechanisms may not be reflected in this document. Changes may have been made to this work since it was submitted for publication. A definitive version was subsequently published in International Journal of Heat and Fluid Flow, 11, 1, (March 1990) DOI 10.1016/0142-727X(90)90022-4

\section{Original Citation}

Wangskarn, P., Ghorashi, B., , \& Gorla, R. (1990). A numerical solution for the turbulent flow of nonNewtonian fluids in the entrance region of a heated circular tube. International Journal of Heat and Fluid Flow, 11(1), 40-43. doi:10.1016/0142-727X(90)90022-4

\section{Repository Citation}

Wangskarn, Prapat; Ghorashi, Bahman; and Gorla, Rama Subba Reddy, "A Numerical Solution for the Turbulent Flow of Non-Newtonian Fluids in the Entrance Region of a Heated Circular Tube" (1990). Chemical \& Biomedical Engineering Faculty Publications. 70.

https://engagedscholarship.csuohio.edu/encbe_facpub/70

This Article is brought to you for free and open access by the Chemical \& Biomedical Engineering Department at EngagedScholarship@CSU. It has been accepted for inclusion in Chemical \& Biomedical Engineering Faculty Publications by an authorized administrator of EngagedScholarship@CSU. For more information, please contact library.es@csuohio.edu. 


\title{
A numerical solution for the turbulent flow of non-Newtonian fluids in the entrance region of a heated circular tube
}

\author{
P. Wangskarn,* B. Ghorashi* and R. S. R. Gorla† \\ Cleveland State University, Cleveland, $\mathrm{OH} 44115$, USA
}

\begin{abstract}
Numerical solutions of conservation equations are obtained for turbulent flow of nonNewtonian fluids in a circular tube. The forward marching procedure of Patankar and Spalding ${ }^{1}$ was implemented in order to obtain the simultaneous development of the velocity and temperature fields by using the apparent viscosity of fluids. Prandtl's mixing length concept is used to determine the apparent turbulent shearing stress. Furthermore, local and average Nusselt numbers are obtained in the entrance region, as well as in the fully developed region. For the case of the fully developed region, values of the Nusselt numbers are compared both with the experimental data and empirical correlations.
\end{abstract}

Keywords: non-Newtonian fluids; power-law fluids; entrance region; developing region

\section{Introduction}

Convective heat transfer to non-Newtonian fluids in tubes is a problem of practical significance. The non-Newtonian behavior of certain fluids is experienced in many industrial applications, such as those that require the use of solutions or melts of polymer materials, petroleum, and pharmaceuticals, as well as many other suspensions and emulsions. Until now, no study has been reported in the literature concerning the simultaneous thermal and hydrodynamic developing region of non-Newtonian fluids. Only certain limited conditions, such as the case of the fully developed velocity profile with developing temperature profile (Notter and Sleicher, ${ }^{2}$ Edwards and Smith, ${ }^{3}$ and $\mathrm{Ju}$ and $\mathrm{Chou}^{4}$ ) or the developing velocity profile in the absence of heat transfer (Dodge and Metzner, ${ }^{5}$ Bowlus and Brighton, ${ }^{6}$ Mizushina et al., ${ }^{7}$ and Salami ${ }^{8}$ ), have been developed for both Newtonian and non-Newtonian fluids under turbulent flow regime in a tube. It should be noted, however, that Emery and Gessner $^{9}$ have computed velocity and temperature profiles for turbulent flow of a non-Newtonian fluid in the entrance region of heated parallel plates, which constitutes a different geometry.

The purpose of this study was to solve the entrance region problem, where both the velocity field and temperature field are simultaneously developing in the case of turbulent flow of non-Newtonian fluids in a circular tube. These results should provide insight into the operation and design of heat transfer equipment. We begin the computations at the tube inlet, assuming that the fluid has uniform velocity and temperature and using only the following conditions:

$$
U(0, y)=U_{0}, \quad U(x, 0)=0, \text { and } \quad V(x, 0)=0 \quad \text { for } x>0
$$

From these conditions, it is assumed that there is no slip velocity at the wall.

\section{Numerical approach}

The field equations that represent incompressible twodimensional (2-D) flow in a tube are

$$
\begin{aligned}
& \frac{\partial}{\partial x}(r U)+\frac{\partial}{\partial r}(r V)=0 \\
& U \frac{\partial U}{\partial x}+V \frac{\partial U}{\partial r}=-\frac{1}{\rho} \frac{d P}{d x}+\frac{1}{\rho r} \frac{\partial}{\partial r}(r \tau) \\
& \text { and } \\
& U \frac{\partial T}{\partial x}+V \frac{\partial T}{\partial r}=\frac{\alpha}{r} \frac{\partial}{\partial r}\left(r \frac{\partial T}{\partial r}\right)-\frac{1}{r} \frac{\partial}{\partial r}\left(r \overline{u^{\prime} T^{\prime}}\right)
\end{aligned}
$$

where $U$ is determined from Equation 2 by using the technique of Patankar and Spalding ${ }^{1}$ and $V$ is found from the continuity equation, Equation 1. By introducing Prandtl's mixing length, we can express the turbulent shear stress as

$\overline{u^{\prime} v^{\prime}}=-l^{2} \frac{\partial u}{\partial y}\left|\frac{\partial u}{\partial y}\right|$

Furthermore, assuming that the turbulent Prandtl number is equal to 1 , we can define the temperature deviation as follows:

$\overline{u^{\prime} T^{\prime}}=-l^{2}\left|\frac{\partial u}{\partial y}\right| \frac{\partial T}{\partial y}$

It is further assumed that the mixing length, $l$, is given by ${ }^{1}$

$$
\begin{aligned}
\frac{l}{\delta}= & 0.41\left(1-e^{-y^{+} / 26}\right)\left(\frac{y}{\delta}\right), \quad \frac{y}{\delta}<0.1 \\
\frac{l}{\delta}= & 0.41\left(1-e^{-y^{+} / 26}\right)\left(\frac{y}{\delta}\right)-1.53506\left(\frac{y}{\delta}-0.1\right)^{2} \\
& +2.75625\left(\frac{y}{\delta}-0.1\right)^{3}-1.88425\left(\frac{y}{\delta}-0.1\right)^{4}, \quad 0.1 \leq \frac{y}{\delta} \leq 0.6
\end{aligned}
$$

$\frac{l}{\delta}=0.089, \quad 0.6 \leq \frac{y}{\delta}$ 
The momentum boundary layer thickness, $\delta$, is derived from the integral momentum equation as

$\frac{d \phi}{d x}+\frac{2 \phi+\delta^{*}}{U_{\mathrm{c}}} \frac{d U_{\mathrm{c}}}{d x}=\frac{f}{2}$

where

$\phi=\left[\frac{c_{1}}{\left(c_{1}+1\right)\left(c_{1}+2\right)}\right] \delta=\left[\frac{c_{1}}{\left(2 c_{1}+1\right)\left(2 c_{1}+2\right)}\right] \frac{\delta^{2}}{R}$

$c_{1}=\frac{2-\beta(2-n)}{\beta n}$

$\beta=-0.05978 \ln (n)+0.25$

$\delta^{*}=\left[\frac{n \beta}{n \beta+(2-\beta(2-n))}\right] \delta-\left[\frac{n \beta}{n \beta+2(2-\beta(2-n))}\right] \frac{\delta^{2}}{2 R}$

The friction factor within the boundary layer of a tube is the modified form of the one proposed by Skelland ${ }^{10}$ for flat plate as follows:

$\frac{f}{2}=\frac{\Psi}{n \beta+1}\left[\frac{(n \beta+1) \Omega}{\Psi}\right]^{1 /(n \beta+1)} \operatorname{Re}^{\prime-\beta /(\beta n+1)}\left(\frac{x}{D}\right)^{-n \beta /(n \beta+1)}$

where

$\Psi=\frac{2-\beta(2-n)}{2(1-\beta+\beta n)}-\frac{2-\beta(2-n)}{2-2 \beta+3 \beta n}$

$\Omega=\frac{\omega(0.817)^{2-\beta(2-n)}}{2^{\beta n+1}}$

$\omega=9.49122 \times 10^{-3} \ln (n+0.0785)$

Now, $T$ can be calculated from Equation 3 by using an explicit finite-difference method. Once the temperature distribution is known for any axial distance, the local Nusselt number can be evaluated. For constant wall temperature,

$\mathrm{Nu}_{x}=-2 \frac{\left(\partial \theta / \partial R^{+}\right)_{\mathrm{w}}}{1-\theta_{\mathrm{m}}}$ where

$\theta=\frac{T-T_{0}}{T_{\mathrm{w}}-T_{0}}$

For constant heat flux

$\mathrm{Nu}_{x}=\frac{2}{\theta_{\mathrm{w}}-\theta_{\mathrm{m}}}$

where

$$
\begin{aligned}
\theta & =\frac{T-T_{0}}{q R / k} \\
\theta_{\mathrm{m}} & =2 \int_{0}^{1} \theta U R^{+} d R^{+}
\end{aligned}
$$

Finally, the average Nusselt number is

$\mathrm{Nu}_{\mathrm{m}}=\frac{1}{x} \int_{0}^{x} \mathrm{Nu}_{x} d x$

\section{Results and discussion}

The ultimate test of a numerical method is to compare the calculated results with experimental data. Experimental data in the entrance region are not readily available for turbulent flow of a non-Newtonian fluid in a tube. The only way to determine the accuracy of the present results is to compare them with solutions to the case of the fully developed flow. Therefore we compared our numerical results with the case of Newtonian fluids, using the correlations of Colburn, Dittus, and Boelter and Kaufman and Isley, as shown in Table 1. For non-Newtonian fluids, we compared our results with experimental values obtained by Yoo, ${ }^{11}$ as shown in Tables 2 and 3 .

It is evident that higher Reynolds numbers result in higher Nusselt numbers, which was expected because of the formation of eddies at the tube wall. However, results show that higher Reynolds numbers require longer entrance regions before the velocity and temperature become fully developed. Both the constant wall temperature and constant heat flux cases were

\section{Notation}

$c_{1} \quad$ Power-law coefficient as defined by Equation 11

$D$ Tube diameter, $\mathrm{m}$

$f \quad$ Friction factor

$n \quad$ Flow behavior index

$\mathrm{Nu}_{\mathrm{m}}$ Average Nusselt number

$\mathrm{Nu}_{x} \quad$ Local Nusselt number

$q \quad$ Heat flux at the wall, $\mathrm{W} / \mathrm{m}^{2}$

$P \quad$ Pressure

$R \quad$ Tube radius, $\mathrm{m}$

$R^{+} \quad$ Dimensionless radial coordinate, $r / R$

$r \quad$ Radial coordinate, $m$

$\mathbf{R e}^{\prime} \quad$ Generalized Reynolds number

$T \quad$ Time average temperature, ${ }^{\circ} \mathrm{C}$

$T^{\prime} \quad$ Fluctuating temperature, ${ }^{\circ} \mathrm{C}$

$U$ Time average axial velocity, $\mathrm{m} / \mathrm{s}$

$U_{c} \quad$ Time average core velocity, $\mathrm{m} / \mathrm{s}$

$u^{\prime} \quad$ Fluctuating axial velocity, $\mathrm{m} / \mathrm{s}$

$V$ Time average radial velocity, $\mathrm{m} / \mathrm{s}$

$v^{\prime} \quad$ Fluctuating radial velocity, $\mathrm{m} / \mathrm{s}$ $x \quad$ Axial coordinate, $\mathrm{m}$

$y^{+} \quad$ Dimensionless distance normal to the wall, $y^{+}=\rho U y / \mu_{\mathrm{a}}$

$l \quad$ Mixing length, $\mathrm{m}$

Greek letters

$\rho \quad$ Density, $\mathrm{kg} / \mathrm{m}^{3}$

$\mu_{\mathrm{a}} \quad$ Apparent viscosity, $\mathrm{kg} / \mathrm{m} \cdot \mathrm{s}$

$\tau \quad$ Shear stress, $\mathrm{kg} / \mathrm{m} \cdot \mathrm{s}^{2}$

$\alpha \quad$ Thermal diffusivity

$\delta \quad$ Boundary layer thickness, $\mathrm{m}$

$\phi \quad$ Momentum thickness, $\mathrm{m}$

$\delta^{*} \quad$ Displacement thickness, $m$

$\beta \quad$ Coefficient as defined by Equation 12

$\Psi \quad$ Coefficient as defined by Equation 15

$\Omega \quad$ Coefficient as defined by Equation 16

$\omega \quad$ Coefficient as defined by Equation 17

$\theta \quad$ Dimensionless temperature

$\theta_{w} \quad$ Dimensionless temperature at the wall

$\theta_{\mathrm{m}} \quad$ Mean dimensionless temperature 
Table 1 Comparisun between other correlations and present model Nusselt number in the fully developed region, $n=1.0$

\begin{tabular}{ccccc}
\hline Re & Colburn & $\begin{array}{c}\text { Dittus and } \\
\text { Boelter }\end{array}$ & Present model & $\begin{array}{c}\text { Kaufman and } \\
\text { Isley }\end{array}$ \\
\hline 28,326 & 231.45 & 283.90 & $301.58(66.22)$ & 312.51 \\
32,372 & 257.54 & 315.90 & $324.66(72.25)$ & 349.59 \\
36,419 & 283.25 & 347.14 & $345.90(96.34)$ & 385.96 \\
40,465 & 308.16 & 377.66 & $374.96(108.39)$ & 421.67 \\
\hline
\end{tabular}

Table 2 Comparison between experimental and predicted Nusselt number in the fully developed region, $n=0.8382$

\begin{tabular}{cccc}
\hline Re & Experimental Nu & Predicted Nu & Mixing length \\
\hline 15,600 & 200.84 & 233.14 & 60.20 \\
18,716 & 232.51 & 269.20 & 66.22 \\
21,856 & 264.00 & 276.62 & 72.25 \\
23,451 & 295.11 & 305.87 & 84.29 \\
25,062 & 310.91 & 328.59 & 90.32 \\
28,000 & 362.65 & 348.14 & 96.34 \\
\hline
\end{tabular}

Table 3 Comparison between experimental and predicted Nusselt number in the fully developed region, $n=0.8924$

\begin{tabular}{cccc}
\hline Re & Experimental Nu & Predicted Nu & Mixing length \\
\hline 11,000 & 149.91 & 207.17 & 42.13 \\
26,580 & 254.54 & 230.88 & 78.27 \\
38,583 & 352.81 & 305.60 & 84.29 \\
41,647 & 383.99 & 330.20 & 90.32 \\
\hline
\end{tabular}

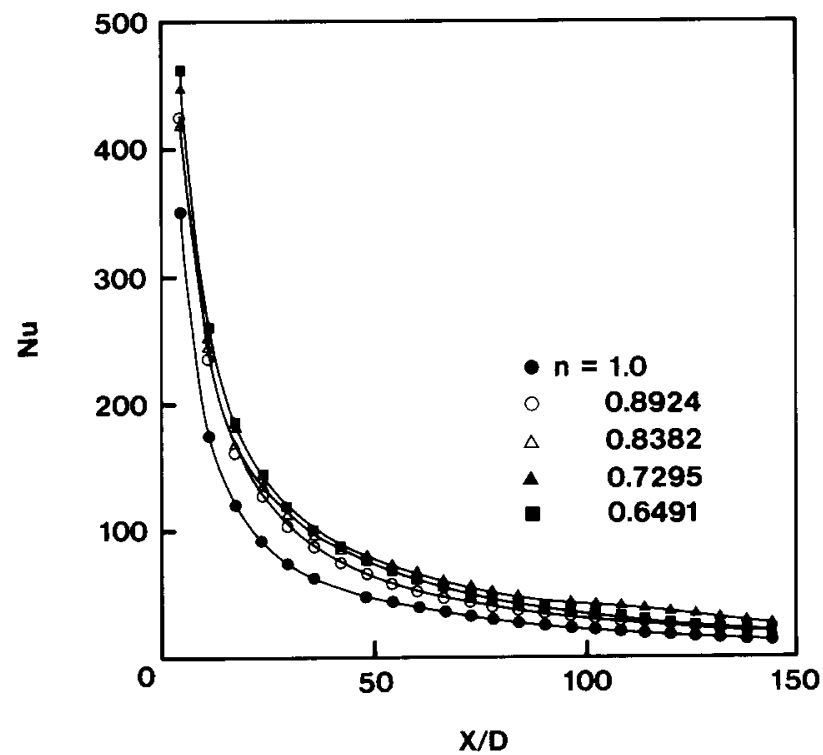

Figure 1 Local Nusselt number in the entrance region, constant wall temperature

studied and the results are illustrated in Figures 1-3. As shown, the flow behavior index, $n$, affects the Nusselt number such that the Nusselt number increases with decreasing flow behavior index. The increase in the mean temperature of the fluid is shown in Figure 4. Also, the effect of wall temperatures on the Nusselt number is presented in Table 4 . The wall temperature clearly does not have any effect on the Nusselt number, as is also evident from the correlations in Table 1.

The effects of Prandtl number on Nusselt number for Newtonian fluids are illustrated in Figures 5 and 6 . Higher Prandtl number fluids should have higher Nusselt numbers. The effect of Prandtl number on Nusselt number is not considered for the case of non-Newtonian fluid because nonNewtonian fluids with the same Prandtl number for a different flow behavior index would have a different Reynolds number.

\section{Conclusions}

Numerical computations based on a mixing-length model are presented for a boundary layer type flow. The findings can be used to predict the local flow behavior of non-Newtonian fluids in the entrance region of a tube. The accuracy of the present method was tested using published data and available empirical

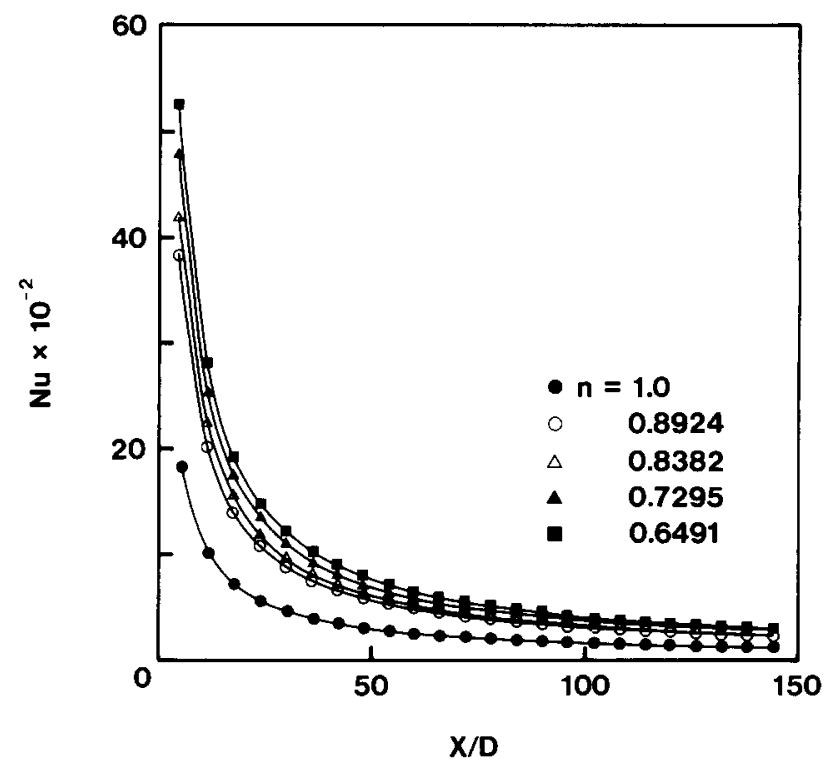

Figure 2 Average Nusselt number in the entrance region

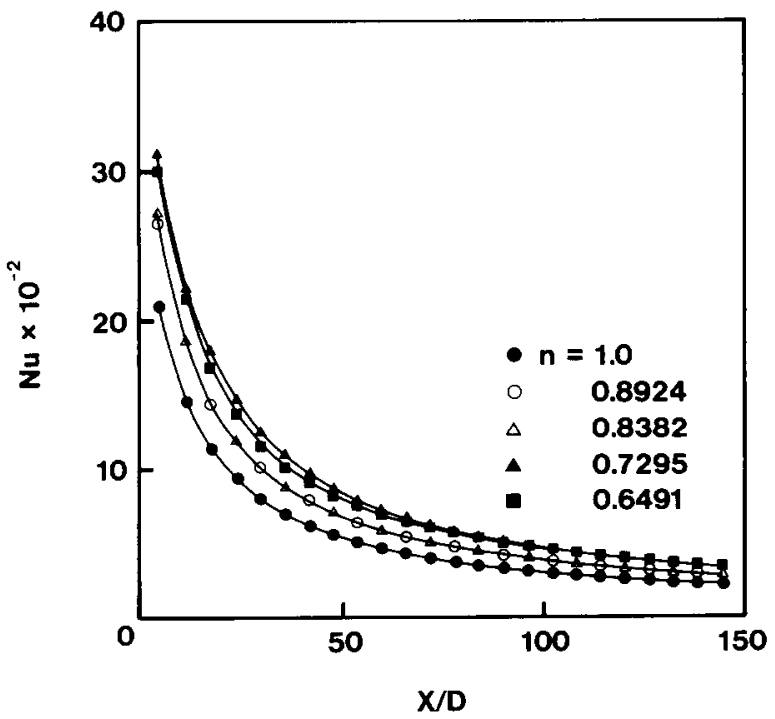

Figure 3 Average Nusselt number in the entrance region, constant heat flux 


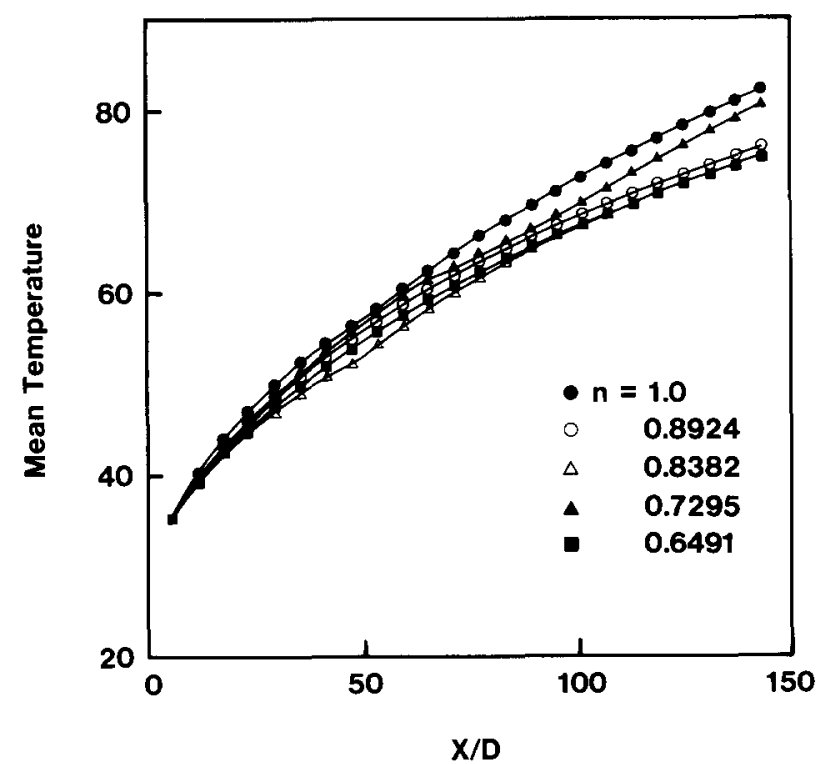

Figure 4 Mean temperature in the entrance region, constant wall temperature

Table 4 Effect of wall temperature $(n=0.8924)$

\begin{tabular}{lcc}
\hline & \multicolumn{2}{c}{$\mathrm{Nu}_{\mathrm{m}}$} \\
\cline { 2 - 3 }$x / D$ & $T_{\mathrm{w}}=100^{\circ} \mathrm{C}$ & $T_{\mathrm{w}}=400^{\circ} \mathrm{C}$ \\
\hline 5.98 & 3836.9 & 3748.2 \\
12.01 & 2030.1 & 2058.2 \\
18.03 & 1411.9 & 1445.7 \\
24.05 & 1098.9 & 1123.8 \\
30.08 & 898.6 & 923.8 \\
36.10 & 770.5 & 786.9 \\
42.10 & 677.1 & 687.1 \\
48.15 & 604.4 & 610.7 \\
54.17 & 546.2 & 550.4 \\
60.20 & 498.6 & 501.5 \\
66.22 & 458.6 & 460.9 \\
\hline
\end{tabular}

correlations for the case of the fully developed region. It should be noted that "entrance data" are not available for the case of non-Newtonian fluids.

Our results show a slight difference between predicted and experimental Nusselt numbers. As expected, both Reynolds number and Prandtl number affect the hydrodynamic and thermal entrance lengths. We have shown that, compared to the Newtonian fluids, pseudoplastics have longer hydrodynamic and thermal entrance lengths. Additionally, pseudoplastic fluids show a higher heat transfer rate than do Newtonian fluids. These results should provide insight into the operation and design of heat transfer equipment.

\section{References}

1 Patankar, S. V. and Spalding, D. B. Heat and Mass Transfer in Boundary Layers, 2nd ed. Intertext Books, London, 1970

2 Notter, R. H. and Sleicher, C. A. A solution to the turbulent Graetz problem---III: Fully developed and entry region heat transfer rates. IChemE. 1972, 27, 2073-2093

3 Edwards, M. F. and Smith, R. The integration of the energy equation for fully developed turbulent pipe flow. Trans. ICheme. $1980,58,259-264$

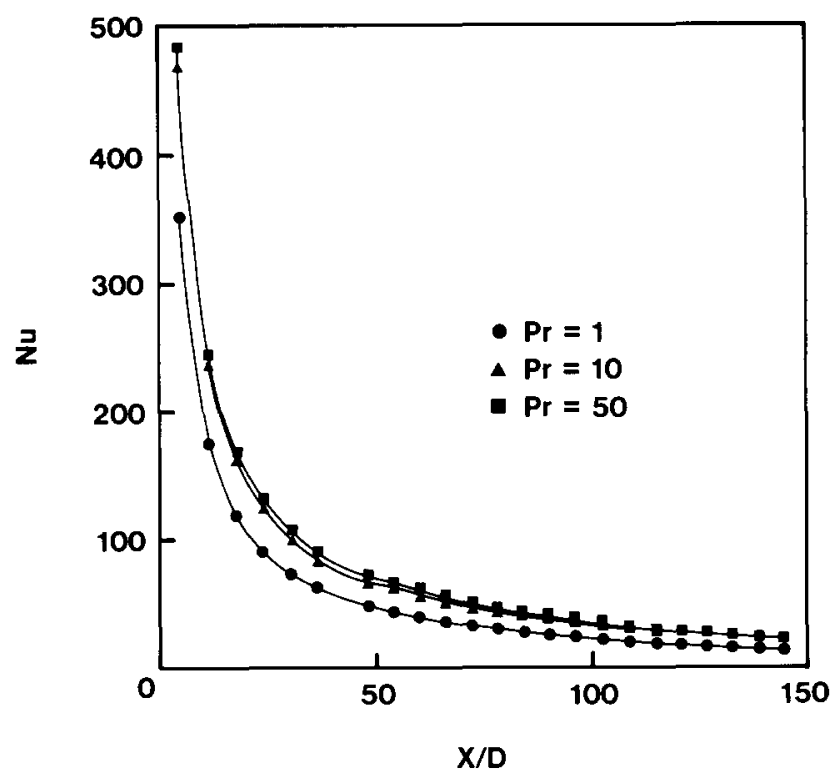

Figure 5 Effect of Prandtl number on local Nusselt number in the entrance region for a Newtonian fluid, constant wall temperature

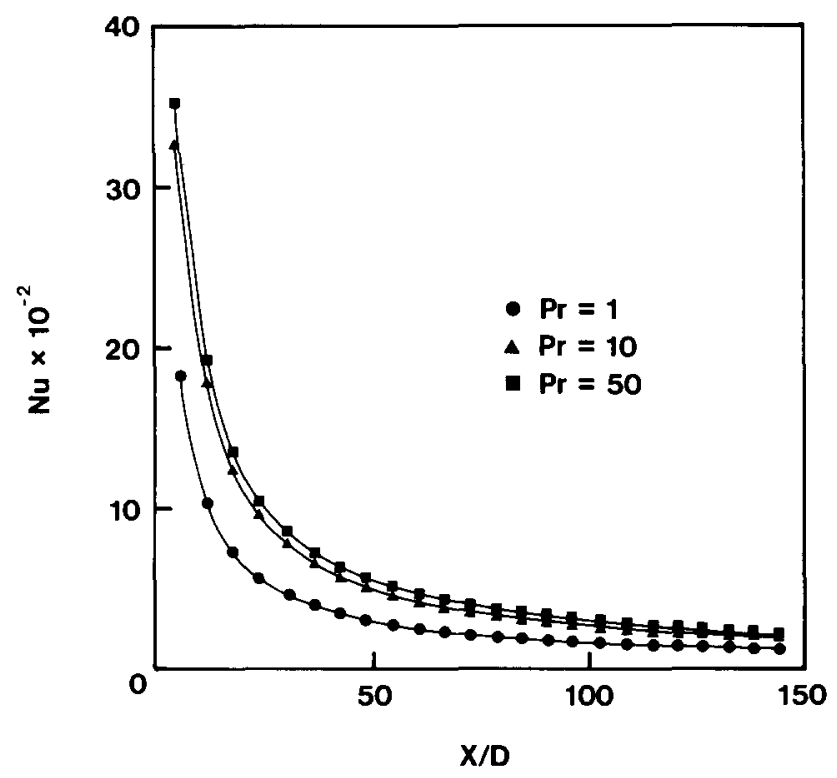

Figure 6 Effect of Prandtl number on average Nusselt number in the entrance region for a Newtonian fluid, constant wall temperature

$4 \mathrm{Ju}, \mathrm{Y}$. H. and Chou, Y. S. Graetz problem of power law fluids in pipes. J. Chi. Inst. Chem. Eng. 1984, 15, 35-40

5 Dodge, D. W. and Metzner, A. B. Turbulent flow of nonNewtonian system. AIChE J. 1959, 5, 189-204

6 Bowlus, D. A. and Brighton, J. A. Incompressible turbulent flow in the inlet region of a pipe. J. Basic Eng. 1968, 431-433

7 Mizushina, T., Ito, R., Ueda, H., Tsubata, S., and Hayashi, H. Flow in the entrance region of a circular tube. J. Chem. Eng. of Japan. 1970, 3, 34-38

8 Salami, L. A. An investigation of turbulent developing flow at the entrance to a smooth pipe. Int. J. Heat and Fluid Flow. $1986,7,247-257$

9 Emery, A. F. and Gessner, F. B. The numerical prediction of turbulent flow and heat transfer in the entrance region of a parallel plate duct. J. of Heat Trans. 1976, 594

10 Skelland, A. H. P. Non-Newtonian Flow and Heat Transfer. John Wiley and Sons, New York, 1967

11 Yoo, S. S. Ph.D. Thesis, Univ. of Illinois, 1974 